Page I19. Rudiments of the wisdom teeth are not usually present in either upper or lower jaw at birth.

Page 132. Fig. 136 could be made much more useful if it showed that the submaxillary ganglion is always found where the lingual nerve crosses the submaxillary duct.

Page 137. No mention is made of the important relation of the external laryngeal nerve to the lateral lobe of the thyroid gland.

Page 623. The statement that "the perinaeal body does not play an important part in the support of the pelvic contents' requires revision. This very useful structure is the common point of insertion of perinaeal muscles, including the pelvic diaphragm, and as a 'point-d'appri' does play an indirect, though vital part, in the support of pelvic viscera.

Page 193. The description of the levator ani here given very much needs correlating with the account of the same muscle given.on page 100.

Page 607. The statement that in spondylolisthesis 'cure cannot be effected' now requires some modification.

Page 558. Recognition of second lumbar ganglion. The ' 2 nd and 3 rd ganglia' should obviously read ' 3 rd and 4 th.'

On page 162, line 14, and page 715, Fig. 721, minor misspellings need correction.

The black and white drawings of Dr. E. A. Thomas continue in increasing number to illustrate the letter-press, and though some may be of doubtful value and too diagrammatic, perhaps, to give the reader a true visual impression of the actual condition, most of them are helpful and are executed with discerning ingenuity and skill.

The above friendly criticisms are made in the hope that this valuable member of the "Synopsis Series' may continue to flourish and even increase its well-deserr $\mathrm{d}$ popularity in future editions.

J.K.

\section{BRITISH ENCYCLOPAEDIA OF MEDICAL PRACTICE}

\section{Vols. 3 and 4}

Edited by The RT. Hon. LORD HoRder, G.C.V.O., M.D., F.R.C.P. Vol. 3: Pp. xvi +707 , with 95 illustrations, and is coloured plates. Vol. 4: Pp. xvi +746 , with I $_{31}$ illustrations. London: Butterworth and Co. 1930. £3 each volume.

There are many changes in the new edition of these two volumes. On turning over the pages one is struck at once by the fact that the illustrations are more numerous and that many more coloured plates of excellent quality have been included. The latter will be welcomed, especially those depicting diseases of the skin and eye.

More than half the total chapters have been recast by new contributors most of whom are already well known by their writing. But some of the chapters by younger newcomers are also of a high order of excellence. One might mention, particularly, the sections on Dyspareunia and Dysmenorrhoea by Mr. J. McClure Brown. The reviewer notes with regret the absence of $\operatorname{Dr} . \stackrel{\frac{0}{O}}{N}$ F. R. M. Walshe's lively pen from the present work, ڤ but hopes that it may appear once more in later 3 volumes.

An important and much needed section on Cor $\stackrel{2}{.}$ Pulmonale by Dr. Paul Wood appears for the first time in Volume 3 , which also includes new chapters on Bursitis and Coccidioimyces. The sections ofo Bronzing of the Skin, Cancer, Canities (which, 들 incidentally, means greying of the hair) and $\bar{c}$. Chordoma have been omitted from the present $\frac{\widehat{\sigma}}{\alpha}$ edition without great loss.

The only new subject included in Volume 4 is Dr. E. G. L. Bywaters' chapter on Crush Syndrome. Perhaps the author's modesty and reluctance to emphasize his own contributions to our knowledge $\vec{\omega}$ on this important subject have resulted in an un- $\sigma$ necessarily brief and contracted account. The chapters in the old edition on Cramp, Sudden 3 . Death, Drug Addiction and Care of the Dying havein been omitted from the present work. No doubt. some sacrifice must be made to allow room for new $w$ matter, but the omission of all these sections is re- $\vec{A}$ gretted. Cramp is a common complaint and, although the subject of recent work in the United States, many doctors continue to be delightfullyo vague about its causes and treatment. Practitionen, called upon to perform the occasional corone autopsy, like to be reminded of the possible causes@ $₫$ sudden death in the difficult case. Drug addiction is probably included in the appropriate sections ons psychological medicine, but the surprising confusion in the index of Volume 3 , which has pages missing or reduplicated, made this point difficult to $\overrightarrow{0}$ check.

Although care of the dying patient depends a gre deal on the personality and skill of the doctor, little emphasis is placed upon it in medical training, while in hospital practice, at all events, it tends to be left to the nursing staff. It is our loss that Professoro John Ryle is no longer with us to write a worthy section on this important subject.

\section{OCCUPATIONAL FACTORS IN THE AETIOLOGY OF GASTRIC AND DUODENAL ULCERS}

M.R.C. Special Report Series No. 276

By Richard Doll, M.D., M.R.C.P., and F. Averyo JoNes, M.D., F.R.C.P. Pp. 96. London H.M.S.O. I95I. 2s. $6 \mathrm{~d}$.

This is a statistical enquiry into the occupationak factors in the aetiology of gastric and duodenalo ulcer. A population of over 6,000 individuals earn $\rightarrow$ ing their livings in various ways has been studied.o They were sub-divided into those with no dyspepsia, those with minor dyspepsia and those with majoro dyspepsia. The last group contained all with recognized ulcer, or with suspected ulcer, and after they had been interviewed by one of the authors, $\omega$ they were finally re-classified into proved peptic ulcer, presumptive ulcer, other dyspepsia and noo dyspepsia. Radiological investigation was carried out when necessary to establish a diagnosis. 
As a result of this survey a number of previously accepted ideas concerning the aetiology of ulcer are discountenanced, further evidence is adduced in favour of others and some new facts emerge. Thus there is no evidence that bus drivers, shift workers or those who have irregular meals show an increased incidence of ulcer. Many gastro-enterologists have thought that gastric and duodenal ulcer are different diseases and it is shown that there is considerable reason for believing this to be so; the relative morbidity differs according to social classes, at different ages and in the two sexes. It is shown that whereas class differences do not affect the development of duodenal ulcer, the incidence of gastric ulcer increases as the social scale is descended. Agricultural workers develop peptic ulcers less often than expected, whereas duodenal ulcer is found more commonly among doctors than in other members of the same social class. It is, however, believed that the latter depends upon the more accurate appreciation of the significance of melaena by members of the medical profession and not upon a true increase in morbidity. The evidence shows that anxiety over work is associated with duodenal ulcer, and it is suggested that this association is more likely to depend upon a common constitutional factor than the direct effect of worry in causing ulcer. Whatever the explanation, the man who worries over his job is more likely than his neighbours to develop a duodenal ulcer, and the lowest paid worker, unless he is lucky enough to be an agricultural labourer, stands the greatest chance of getting a gastric ulcer. For the whole population under survey, 6.5 per cent. of the men and 1.7 per cent. of the women were ulcer subjects, and 24.9 per cent. of the men and 27.8 per cent. of the women had 'other dyspepsias.'

The detailed nature of this painstaking enquiry makes it impossible to summarize it fully in a short review. Anyone interested in the subject should read it for himself. Apart from the information about peptic ulcer, it is a model of statistical research. It is a truism that ' anything can be proved by statistics,' and while this is an obvious exaggeration, it is a weak point of many investigations of this kind that the conclusions drawn from the figures, significant though they may be, are not always valid. The obvious explanation of a significant difference in behaviour between a number of groups is not always the correct one. The authors have in this case taken every care to avoid drawing false conclusions from the figures and have done their best to check possible sources of error.

R.S.B.P.

\section{ETERNAL EVE}

By Harvey Graham. Pp. $x x+699$, illustrated. London: William Heinemann. 1950. 42s.

This book is difficult to read but even more difficult to review. It lacks the appeal of the author's 'Surgeons All,' and the enthusiasm and power of Howard Haggard's 'Devils, Drugs and
Doctors,' though it contains chapters, such as 'The Glory that was Rome' and 'Rabbits and Quacks' that display Dr. Graham's lucid and attractive style at its best.

This is an enormously long book, which does not seem to have gained in value in proportion to its length. The book is also somewhat disjointed in narrative, but it is impossible to escape from the fact that Dr. Graham has read widely and with discernment. He has packed in a mass of factual information, but the whole work leaves the reader unsatisfied. . It is likely to confuse the layman, and he who might lay it aside part finished would command sympathy. The medical historian on the other. hand will miss the detailed bibliography that such a work surely merits. The extra pages would add little in length, but much in value to the historian. If it is really designed for lay consumption, drastic reduction in length would be a great advantage.

In a book such as this it is a great joy to see many original and carefully chosen illustrations.

$$
\text { G.B.L. }
$$

ST. THOMAS'S HOSPITAL REPORTS, Vol. VI Pp. 285, illustrated. London: St. Thomas's Hospital. 1950. 10s. 6d.

This is an interesting and valuable collection of articles and reports from all departments of the hospital, outlining new work, describing current practice or reporting series of cases.

It would be invidious as well as impossible for any reviewer to single out individual articles from so wide a field, but reviews of 490 cases of carcinoma of the bronchus, of 485 cases of cancer of the large bowel and of $3 \mathrm{I}$ cases of Addison's disease obviously give much material for thought; whilst a study of the results of ligation of the spermatic cord in the repair of inguinal hernia, though only concerned with ro cases, none the less provides good reason for condemning the procedure.

\section{HOW I CURED MY DUODENAL ULCER}

By John Parr. Pp. r6o. London: Michael Joseph Ltd. 1951. 8s. 6d.

This little book is the life history of Mr. John Parr's duodenal ulcer which the owner has finally managed to cure with the aid of a special diet. There is also a reasonably clear and sensible account of the various theories of the aetiology of this condition. One can only hope that Mr. Parr continues to have no further trouble with his ulcer, but at the same time one must remain sceptical as to whether the treatment he advocates is really the best treatment for all cases of duodenal ulceration. No doubt this little book will sell well, particularly amongst laymen, but it is a little difficult to see that it will serve any useful purpose. 